TI 2013-038/VII

Tinbergen Institute Discussion Paper
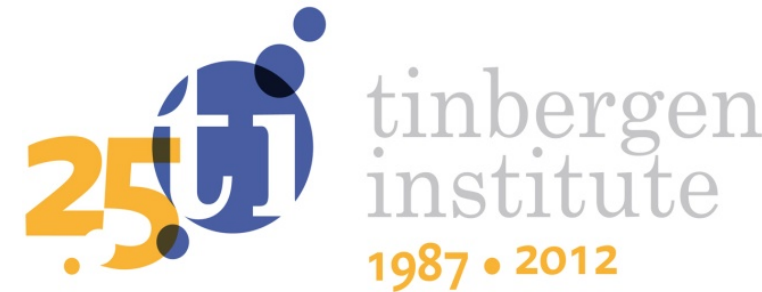

\title{
Employee Recognition and Performance: A Field Experiment
}

\author{
Christiane Bradlerl
}

Robert Dur ${ }^{2}$

Susanne Neckermann²

Arjan Non ${ }^{3}$

1 ZEW Centre for European Economic Research Mannheim;

2 Erasmus School of Economics, Erasmus University Rotterdam, ZEW, and Tinbergen Institute;

3 Maastricht University. 
Tinbergen Institute is the graduate school and research institute in economics of Erasmus University Rotterdam, the University of Amsterdam and VU University Amsterdam.

More TI discussion papers can be downloaded at http://www.tinbergen.nl

Tinbergen Institute has two locations:

Tinbergen Institute Amsterdam

Gustav Mahlerplein 117

1082 MS Amsterdam

The Netherlands

Tel.: +31(0)205251600

Tinbergen Institute Rotterdam

Burg. Oudlaan 50

3062 PA Rotterdam

The Netherlands

Tel.: +31(0)10 4088900

Fax: $+31(0) 104089031$

Duisenberg school of finance is a collaboration of the Dutch financial sector and universities, with the ambition to support innovative research and offer top quality academic education in core areas of finance.

DSF research papers can be downloaded at: http://www.dsf.nl/

Duisenberg school of finance

Gustav Mahlerplein 117

1082 MS Amsterdam

The Netherlands

Tel.: +31(0)20 5258579 


\title{
Employee Recognition and Performance: A Field Experiment*
}

\author{
Christiane Bradler, Robert Dur, Susanne Neckermann, Arjan Non`
}

December 2014

\begin{abstract}
This paper reports the results from a controlled field experiment designed to investigate the causal effect of unannounced, public recognition on employee performance. We hired more than 300 employees to work on a three-hour data-entry task. In a random sample of work groups, workers unexpectedly received recognition after two hours of work. We find that recognition increases subsequent performance substantially, and particularly so when recognition is exclusively provided to the best performers. Remarkably, workers who did not receive recognition are mainly responsible for this performance increase. Our results are consistent with workers having a preference for conformity and being reciprocal at the same time.
\end{abstract}

JEL Classifications: C93, M52.

Keywords: employee motivation, recognition, reciprocity, conformity, field experiment.

${ }^{*}$ We gratefully acknowledge comments and suggestions by a Department Editor, an Associate Editor, three anonymous referees, Iwan Barankay, Gary Charness, Tore Ellingsen, Dirk Engelmann, Guido Friebel, David Gill, Michael Kosfeld, Steve Levitt, John List, Michel Maréchal, Dina Pommeranz, Ingrid Rohde, Marie Claire Villeval, and numerous seminar and conference participants. We thank Ann-Kathrin Koessler for excellent research assistance. The experiment has been conducted within the ethical guidelines of our home institutions.

† ZEW Centre for European Economic Research Mannheim. E-mail: bradler@zew.de.

${ }^{\ddagger}$ Erasmus University Rotterdam, Tinbergen Institute, CESifo, and IZA. E-mail: dur@ese.eur.nl.

$\S$ Erasmus University Rotterdam, ZEW, and Tinbergen Institute. E-mail: neckermann@ese.eur.nl.

ฯ Maastricht University. E-mail: j.non@maastrichtuniversity.nl. 


\section{Introduction}

Recent years have seen a surge in popular business books on the importance of recognition for employee motivation. A prominent example is the book by Nelson (2005) entitled 1001 Ways to Reward Employees. He starts his book by stating that a number of surveys "confirm what almost every employee already knows: that recognition for a job well done is the top motivator of employee performance." ${ }^{1}$ Other questionnaire studies reveal similar views among employees (Kovach, 1995; Wiley, 1997) and managers (Holton et al., 2009).

The vast amount of practitioner literature on employee recognition is supported by a body of academic research. Stajkovic and Luthans (2003) provide a meta-analysis of studies conducted in organizations, and report strong positive effects of recognition on employees' performance. More recently, Grant and Gino (2010) experimentally study how a manager's verbal expression of gratitude affects employees' effort and find strong positive effects. ${ }^{2}$

While the existing literature provides a fairly consistent picture that recognition improves employee performance, much less is known about how exclusive or inclusive recognition should be. Should all employees receive recognition? Or is more differentiation desirable? In particular, what is the effect of exclusive recognition for the best-performing workers on performance of workers who do not receive recognition?

In this paper we take up these questions by conducting a large-scale field experiment in a controlled work environment. Over the course of November 2010 to May 2011, we hired 363 people (mainly students) for a three-hour data-entry job. ${ }^{3}$ We created a work environment where eight workers shared the same room, but worked individually. Workers were paid a flat wage of 25 euro and were not aware that they took part in an experiment. In a random sample of work groups, workers received public recognition after two hours of work. Following Kosfeld and Neckermann (2011), recognition consisted of a thank-you card, personally signed by the head of the research institute and handed out by a research assistant. ${ }^{4}$ Thus, the provision

\footnotetext{
${ }^{1}$ He continues with "yet most managers do not understand or use the potential power of recognition and rewards [...] while money is important to employees, research shows that what motivates them really to perform [...] is the thoughtful, personal kind of recognition that signifies true appreciation for a job well done."

${ }^{2}$ Effects of praise and recognition have also been studied in other contexts. Fisher and Ackerman (1998) investigate the effect of recognition on parents' willingness to volunteer for their kids' soccer club. An early lab experiment is Deci and Ryan (1971) showing that provision of praise increases students' willingness to work on a puzzle. Cameron and Pierce (1994) provide a survey of the subsequent lab-experimental literature. Finally, some studies in management provide correlational evidence, e.g., Rhoades and Eisenberger (2002), Cropanzano and Mitchell (2005), and Wagner and Harter (2006).

${ }^{3}$ Short-term data-entry jobs like ours have been frequently employed in recent field experiments studying the impact of rewards on performance because they allow for a precise measurement of performance and provide for a high degree of control (see among others Gneezy and List, 2006, Hennig-Schmitt et al., 2010, Kosfeld and Neckermann, 2011, and Kube et al., 2012, 2013). The short-term nature of the job enables us to minimize possible career concerns, which greatly facilitates the interpretation of the results. Note that temporary workers are quite prevalent nowadays and "represent an interesting middling ground between subjects in one-shot experiments and full-time employees in firms" (Al-Ubaydli et al., 2014, p. 2).

${ }^{4}$ The use of such thank-you cards is not uncommon in business. Postcards producer Hallmark devotes a separate website to
} 
of recognition did not involve any material reward but clearly showed the management's appreciation for workers' effort. From the way recognition was provided, workers could deduce that no further thank-you cards would be provided in the remainder of the working period. A defining feature of the type of recognition that we have in mind is that it comes as a surprise to employees. ${ }^{5}$ Therefore, and in stark contrast to Kosfeld and Neckermann (2011), the possible provision of recognition was not announced at the start of the three-hour working period. ${ }^{6}$

To address the research questions posed above, we vary the scarcity of recognition between different treatments. In one treatment, all workers in a group receive the thank-you card. In the other treatments, the thank-you card is given only to the best performer so far or to the best three performers so far of a group of eight. When handing out the thank-you cards in these latter treatments, it is mentioned that their assignment is determined by performance during the first two working hours. Further, we make clear that the management recognizes the work input from all workers, but can only recognize a subset of the employees explicitly due to time constraints. This resembles that, in practice, managers are often constrained in the number of people they can praise in a thoughtful, personal way. Lastly, we did our best to keep perceived monitoring constant across all treatments.

Our results are as follows. First, we find that providing public recognition has a positive effect on subsequent performance of workers. When all employees in a work group receive a thank-you card, subsequent performance increases by about $5.2 \%$ (or 0.27 standard deviations) as compared to the untreated control. When public recognition is more exclusive, such that the best 3 out of 8 employees in a work group receive a thank-you card, the estimated effect is even bigger and amounts to a $7.3 \%$ (or 0.38 standard deviations) performance increase. Remarkably, employees who do not receive a thank-you card are mainly responsible for this performance increase. Their performance rises by more than $10 \%$ (or 0.52 standard deviations) relative to comparable others in the control group. Recipients of a thank-you card, on the other hand, show a performance increase of only $3.3 \%$ (or 0.17 standard deviations). When recognition is even scarcer and limited to the single best-performing employee, we find a slightly weaker average treatment effect of about $5.6 \%$ (or 0.29 standard deviations), and a similar pattern with respect to the source of the response, with non-recipients increasing performance by about $6.6 \%$ (or 0.34 standard deviations), while recipients' response is close to zero. Hence, we find that unannounced recognition can be a powerful tool to raise performance, particularly of those employees who do not get it!

employee thank-you cards, see http://hallmark.businessgreetings.com/employeerecognitioncards-employeethankyoucards-3-0.

${ }^{5}$ This is often true in practice, even in organizations with a culture for praise. While recognition in general might be expected in such organizations, the particular situation, timing, and kind of recognition usually remain a surprise. This is not without reason: Rogers and Frey (2014) argue that habituation to stimuli (such as recognition) is less likely if the stimulus is presented at unpredictable time intervals and is not presented in the same way every time.

${ }^{6}$ Thus, while we use the same symbol (a thank-you card), our study differs fundamentally from Kosfeld and Neckermann (2011). While they use the card as an award in a tournament, which is announced before the start of the work, our study looks at the effect of unannounced recognition provided after some time of work on subsequent work performance. We further differ from Kosfeld and Neckermann (2011) by varying the scarcity of recognition. 
As we will argue in more detail below, the underlying mechanisms that explain our results best are that workers have a preference for conformity and are reciprocal at the same time. In the treatments with scarce recognition, non-recipients learn that their performance belongs to the bottom of the distribution, implying that it is more likely that they do not conform to the apparent work norm in the group. Consequently, they feel a need to increase performance. The smaller positive response of non-recipients in the treatment with only one card as compared to the treatment with three cards is in line with this argument, because the signal of relatively low performance to non-recipients is weaker when recognition is very scarce. The positive response to the treatment with recognition for all workers suggests that reciprocity also plays a role. Reciprocity might further explain why we do not observe that recipients of recognition in treatments with scarce recognition reduce their performance, which we would expect if conformity preferences would be the sole mechanism. Following this interpretation, for recipients the negative effect generated by the preference for conformity is neutralized by the positive effect generated by positive reciprocity concerns. Overall, our experimental data suggest that recognition stimulates performance in a workplace setting and that exclusivity can be an effective tool to motivate relatively bad performers to catch up. However, that is only true up to a point: if recognition becomes too scarce, its effectiveness diminishes.

Our study contributes to several literatures. First, we contribute to a substantial body of evidence in the business and psychology literature on the power of employee recognition, in particular Stajkovic and Luthans (2003) and Grant and Gino (2010). A unique feature of our study is that we exogenously vary the scarcity of recognition, ranging from providing recognition to all workers in a work group to recognizing only the best worker. The issue of how exclusive or inclusive recognition should be is of clear relevance for practitioners. Moreover, varying scarcity of recognition allows us to further our understanding of the driving forces of workers' behavior, such as reciprocity and conformity preferences. We also contribute to the growing literature in economics documenting the power of nonfinancial work interventions. Most closely related are the papers looking at nonfinancial gift-exchange, employee awards, and performance feedback. A prominent recent example is Kube et al. (2012), who find that nonfinancial gifts are more effective at increasing worker performance than financial ones. In contrast to that study, we provide recognition that has no material value and vary its scarcity. Moreover, we provide recognition for a job well done after some time of working, while Kube et al. (2012) provide gifts at the start of the job. In our treatments with scarce recognition, it is provided conditional on past performance, which is another important departure from most gift-exchange studies. Other recent papers have studied nonfinancial awards as incentives (Kosfeld and Neckermann, 2011; Gubler et al., 2013; Anderson et al., 2013; Ashraf et al., 2014a,b; Bareket-Bojmel et al., 2014). We complement this literature by studying recognition that is not announced in advance, but comes as a surprise. Lastly, we contribute to the literature on the effects of relative performance feedback on workers' performance (Blanes i Vidal and Nossol, 2011; Barankay, 2011a,b; Delfgaauw et al., 2013). ${ }^{7}$

\footnotetext{
${ }^{7}$ Other contexts in which relative performance feedback have been studied include student test scores (Bandiera et al., 2009; Azmat and Iriberri, 2010; Tran and Zeckhauser, 2012), contributions to an online community (Chen et al., 2010), and real-effort in the lab (Charness et al., 2014; Freeman and Gelber, 2010; Kuhnen and Tymula, 2012).
} 
A distinguishing feature of our study is that we look at ex post effects of coarse rank revelation that is not announced ex ante and in the absence of further rank concerns (as ranks will not be disclosed again). Most of the empirical papers as well as the theoretical literature center around the effect of rank revelation in ongoing tournaments. Moreover, in our study the relative performance feedback always comes with a clear signal of the employer's appreciation of the employee's performance.

Our main and novel findings are that unannounced recognition in the workplace is most effective for intermediate levels of scarcity, and that non-recipients are mainly responsible for the performance increase. These findings have interesting management implications. In practice, managers may worry about making recognition scarce as they fear negative responses from the non-recipients. Our results suggest that this fear is unwarranted. Further, our results suggest that scarce recognition can be a cost-effective tool to motivate the workers at the bottom of the productivity distribution. This finding is particularly informative for organizations who care strongly about the performance of their least productive employees. For instance, in mass production it is often the productivity of the least motivated employee on the assembly line that determines the quality of the end product and the length of the production time. Lastly, our evidence suggests that workers care about conforming to a prevailing work norm and that scarce recognition can be a powerful way to communicate this norm to workers. ${ }^{8}$ Hence, the mechanism that we isolate should be particularly relevant and active whenever workers face some uncertainty about the prevailing work norm. Such situations are commonplace, for instance in organizations with high employee turnover and regularly changing team composition.

The paper proceeds as follows. In the next section, we draw on existing behavioral theories to develop hypotheses on the effects of different forms of recognition. Next, we describe the experimental setup in Section 3. Section 4 lays out the empirical strategy and presents the results of our experiment. Finally, Section 5 concludes.

\section{Theory}

Why might the unannounced provision of recognition in the form of a thank-you card affect subsequent performance of workers? And does it matter whether all workers or only the best performing workers in a group receive a thank-you card? We can think of three plausible behavioral mechanisms through which provision of public recognition may affect subsequent performance. ${ }^{9}$

\footnotetext{
${ }^{8}$ Conformity preferences have been found to be important drivers of behavior in lab experiments on work motivation (Danilov and Sliwka, 2013; Bicchieri and Xiao, 2009) as well as in several other contexts, such as energy consumption (Schultz et al., 2007; Nolan et al., 2008; Allcott and Rogers, 2014), charitable donations (Frey and Meier, 2004; Shang and Croson, 2009; Alpizar et al., 2008), tax compliance (Bobek et al., 2007), and voter turnout (Gerber and Rogers, 2009).

${ }^{9}$ See the working version of this paper for a formal exposition of the theoretical arguments (Bradler et al., 2013a).
} 
Reciprocity of employees First, workers may consider the thank-you card as a gift from the employer and feel inclined to reciprocate. A natural way to reciprocate is to increase subsequent work effort. According to Blau (1964), the reason that gifts are reciprocated is that people "are interested in maintaining a balance between inputs and outputs and staying out of debt in their social transactions" (p. 26). Following the seminal paper by Akerlof (1982) and the influential experimental work by Fehr et al. (1993), reciprocity has become a firmly established concept in economics. Most studies in economics have focused on wages as the employer's means of exchange in reciprocal relationships with workers. An exception is Kube et al. (2012), who show that non-pecuniary gifts are particularly powerful in triggering subsequent work effort. Other social sciences have also considered socio-emotional gifts that address "social and esteem needs (and are often symbolic and particularistic)" (Cropanzano and Mitchell, 2005, p. 881). The thank-you card, which is central to our treatments, clearly falls into this latter category. Naturally, in treatments where only a subset of workers receives a thank-you card, we only expect recipients to respond. Moreover, scarcity may increase the perceived value of the card. Insofar as this holds, recipients should respond more strongly when the number of cards is smaller.

Conditional altruism of employees A second reason for why the provision of a thank-you card may affect subsequent effort is that the card provides a signal to the workers about the employer's kindness or his care for the workers. The key assumption is that workers are conditionally altruistic, that is, they care more for an employer who cares for them. As a result, workers respond with increased effort when they perceive the thank-you card as a credible signal of the employer's kindness (see Levine, 1998, and more recently Dur, 2009, and Non, 2012). This tendency to contribute to the welfare of a kind person can be seen as a form of reciprocity, but it has implications that are different from those of reciprocity discussed above, particularly for the response of non-recipients, According to conditional altruism, provision of public recognition should affect effort of recipients and non-recipients identically, as all workers receive the same signal on employer kindness. Effort responses should vary across our treatments as the scarcity of recognition affects perceived kindness. In particular, providing just a few cards may be seen as a weaker signal of kindness than providing all workers with a thank-you-card. Hence, conditional altruism predicts that recognition raises the performance of all workers and that this increase is the stronger the more cards are provided. ${ }^{10}$

Conformity preferences of employees Third and last, in both treatments with scarce recognition, preferences for conformity may lead to subsequent performance changes. Recipients in these treatments learn that their performance belongs to the top within their group. Likewise, non-recipients learn that they belong to the lower end of the performance distribution. If workers have a preference for conformity (for

\footnotetext{
${ }^{10}$ Other models that formalize intentions yield similar predictions, e.g. Falk and Fischbacher (2006) and Gul and Pesendorfer (2010). Alternatively, the thank-you card may affect workers' beliefs about how important the task is to the employer (as in, for example, Benabou and Tirole, 2003, and Swank and Visser, 2007) or about whether the principal is worth impressing (as in the model of Ellingsen and Johannesson, 2008). These theories yield similar predictions.
} 
example, if they want to behave like others or to adhere to a group norm as in Bernheim, 1994, Sliwka, 2007, Fischer and Huddart, 2008, and Chen et al., 2010), then this coarse rank information should decrease effort of recipients and increase effort of non-recipients. We expect weaker effects for non-recipients in the treatment where only a single thank-you-card is provided to the best performer than in the treatment where the three best-performing workers receive a thank-you card. The reason is that non-recipients receive more information about their relative performance when they learn that they are among the bottom 5 out of 8 in the group than when they learn that they are not the best in the group. Conversely, recipients of the card should respond more strongly when fewer thank-you cards are distributed, as this provides a stronger signal of exceptionally high performance by the recipients. Lastly, on the basis of conformity preferences alone, we do not expect any treatment effects when all workers are provided with a thank-you card, since nothing is revealed about relative performance in this treatment.

Table 1 summarizes our theoretical predictions.

\section{Design and Implementation}

\subsection{Background}

In order to estimate the causal effect of recognition on employee performance, we conducted a natural field experiment following the methodology as laid out by Harrison and List (2004), Levitt and List (2009), and List and Rasul (2011). ${ }^{11}$ This means that we observed workers in a controlled work environment and that workers were not aware of the fact that they were part of an experiment. On behalf of a German research institute - the Centre for European Economic Research (ZEW) - we hired students for a one-time data-entry job between November 2010 and May 2011. At the time, the institute had just received several hundreds of completed surveys that could not be processed automatically, which made manual entry into a database necessary. For this job, we recruited students at different universities in and around Mannheim via student job centers, flyers, and notes on bulletin boards. The announcement informed people that the research center needed short-term student helpers for a three-hour data-entry job and that workers would receive a fixed wage of 25 euro. ${ }^{12}$ Students could sign up for the job online and were subsequently contacted by phone to arrange date and time of their assignment. We minimized career concerns by informing workers that the job was one-time, that a second participation was not possible for tax reasons, ${ }^{13}$ and that the research team was

\footnotetext{
${ }^{11}$ We conducted two additional experiments in the same setup. The results are reported in Bradler and Neckermann (2013) and Bradler et al. (2013b). All regressions reported below include observations from and dummies for the treatments in these experiments to obtain more accurate estimates for the coefficients of the control variables. All results are robust to not including these data in the regression analyses.

12 The fixed wage corresponds to a typical hourly wage of students for this kind of short-term job.

${ }^{13}$ In case of a second participation, workers would exceed the threshold of earnings beyond which tax-based information needs to be collected. This would cause substantial administrative effort for fiscal reporting and was, hence, not desired by the research
} 
not looking for permanently employed research assistants at the moment. We invited workers in groups of eight. Sessions took place at two different locations and three different times of the day (morning, noon, and afternoon). ${ }^{14}$ Following Kosfeld and Neckermann (2011), we implemented recognition by handing out thank-you cards (see Figure 1) to employees. In contrast to Kosfeld and Neckermann (2011), provision of thank-you cards was not announced at the start of the working period. Instead, they were unexpectedly provided after two hours of work to either all or a subset of employees in the work session depending on the treatment. After this interruption, employees worked for another hour.

\subsection{Implementation}

Upon arrival, workers chose a workstation and were assigned a login code for the data-entry surface. The workspaces were arranged in a U-shape with sufficient space between individuals to ensure that they felt unobserved. After all formalities (privacy policy, wage agreement) were taken care of, the fixed wage of 25 euro was paid in advance to stress that payment was independent of work performance. Subsequently, the workers received a short introduction to their employer (ZEW) and to the project that the surveys stemmed from. The pen-and-paper surveys were part of an evaluation project in the educational context and involved responses from several hundreds of students to questions about their school and career preferences. Additionally, a short briefing was given on how to file the answers from the questionnaires into the database. As the data were filed via a web interface, access to the internet was visible and possible at any time. The interface was set up as an online version of the paper surveys that the workers had in front of them. Most survey questions were multiple choice, only a few questions required entering information from free text fields. To minimize productivity spillovers between workers (e.g. peer effects as in Falk and Ichino, 2006), questionnaires were stacked in a high, non-transparent box placed in front of each worker, with an identical box next to it to deposit the completed ones.

After the instructions were given, the research assistant left the room. She informed employees that she was working outside and was available for queries at any time. She also said that they could take breaks whenever necessary. These measures (individual breaks, payment in advance, internet access, and absence of supervisor) were taken to give workers substantial leeway in the amount of time they spend on filling the database. They are not uncommon for this type of job at this research institute. Furthermore, a collective break was avoided to minimize possible group effects and communication between workers. ${ }^{15}$ Before the start of the instructions, the research assistant publicly made note about which workstation was used by

institute.

14 The field experiment was carried out at the Centre for European Economic Research (ZEW) in Mannheim and the Ruprecht-Karls University of Heidelberg. In the regressions we control for time-of-day as well as for location effects, but dropping these controls does not affect the results. All sessions were conducted by the same research assistant.

${ }^{15}$ Because the assistant was sitting outside, we have no perfect monitoring of the amount of communication in the room. However, the research assistant was sitting close to the door and could hear everything that was said loudly. According to her, the extent of communication was minimal in all sessions. 
whom. Thus, workers were aware of the fact that login codes of a workstation could be linked to their person, which should help to hold perceived monitoring constant across treatments.

Eight workers were assigned to each work session. However, since some workers did not show up, the average number of workers per session was 7.21 (s.d. = 0.87). The timeline was as follows: the formalities and introduction lasted for about 18 minutes on average. Then, employees worked on the task for roughly 102 minutes. We refer to this phase as working period $1 .{ }^{16}$ Subsequent to working period 1 (i.e., two hours after employees' official start of work), the research assistant entered the room and told workers that she had just checked the server with the help of the IT-department to ensure that the data were transmitted correctly from each computer to the central data base. She informed workers that this was necessary as there had been server problems in the past. ${ }^{17}$ Depending on the treatment, she did or did not provide recognition by handing out thank-you cards, following a standard procedure described in the next subsection. After this intervention, employees worked for approximately one additional hour - which we refer to as working period 2. ${ }^{18}$ Working period 1 was longer than working period 2 to allow for variation in the length of the introductory period and to let learning effects smooth out, which we believed to be largest at the beginning of working period 1. After the second working period, feedback forms were handed out, which asked for improvement suggestions and comments on how we handled the short-term employment. These forms allowed us to gather information on field of study.

\subsection{Treatments}

As described above, the treatment interventions took place after working period 1. The different scripts can be found in Appendix A. In all treatments, including the control treatment, the research assistant informed workers that there had been some software problems in the past, but that in this session all the data were transmitted correctly from all computers to the central server. Nothing else happened in the Control treatment, so that we can measure the development of productivity without recognition but with disruption. In treatments involving thank-you cards, she continued by saying that the research team, together with the president of the institute, had created thank-you cards as a symbol of the institute's gratitude and appreciation of the workers' support in entering the data. To ensure that the card would be considered as a clear signal of appreciation, all cards were personally signed by the head of the institute, president Professor Franz, see

\footnotetext{
${ }^{16}$ The standard deviation of the introductory period is 5 minutes. Differences in length are due to delays in arrival of workers and differences in the number of questions that were asked during the introduction. The standard deviation of the duration of working period 1 is $6.6 \mathrm{~min}$. Differences in the lengths of working period 1 are mainly due to delays in the introductory period.

17 The data transmission could only be checked with the help of the IT department who had access to the server. Therefore, we had to request whether the data transfer was successful in every session, and workers were informed about this to make them aware of the fact that we can observe the data transfer from each computer. As technical problems occurred in the first sessions, we decided to give this information in all later sessions too.

18 The mean length of working period 2 is 54.2 min with a standard deviation of $4.1 \mathrm{~min}$. We account for differences in the length of working periods in the statistical analysis by using productivity per minute of working time as the dependent variable. Additionally, we control for the length of working period 1 in the regressions.
} 
Figure 1.

We implemented the following treatments. In the treatment "Thank-you card for all" (TC All), the research assistant handed a card to each worker. This treatment allows us to measure the response to general appreciation and recognition. In the treatment "Thank-you card for the best 3" (TC Best3), workers were informed that the research assistant had only a limited number of cards available, and that it had just been decided to hand these out to those three persons who had performed best until then. ${ }^{19}$ The treatment "Thank-you card for the best 1" (TC Best1) was identical to TC Best3 apart from the fact that there was only one recipient of a thank-you card, the worker who performed best in the first working period.

The scarcity of cards was explained by saying that the president did not manage to sign a card for each worker. ${ }^{20}$ This excuse renders it unlikely that workers expect additional cards at the end of working period 2 and makes sure that workers knew that there was a practical reason for making recognition scarce. As there were fewer than eight workers in some sessions, we adjusted the number of cards in accordance to the actual group size to keep the percentage of workers who received cards comparable. ${ }^{21}$

Since sessions took place over the course of several months, we cannot rule out that workers in later sessions heard about treatments in earlier sessions. We took two measures to address this concern. First, we conducted most sessions of the more salient treatments (TC Best3, TC Best1) subsequent to the less salient treatments (Control, TC All). However, we also had a few later sessions of the less salient treatments (Control, TC All) to be able to control for time effects. Second, we elicited how people learned about the job in the feedback form at the end of the employment. Only a handful of workers indicated that they had learned about the job from a friend. The exclusion of these workers from the analysis does not change the results.

\footnotetext{
${ }^{19}$ We measured performance in terms of the number of finished questionnaires in working period 1 . Workers were told that the IT department had informed the research assistant which three logins had performed best. Hence, in all treatments, including the control, workers knew that the research assistant herself could not directly observe the performance of workers in real-time.

${ }^{20}$ Even though it does not seem to be a lot of work for the president to sign a few more cards, note that in total we employed more than 300 people. Although workers were not aware of the total number of people working for us, they were able to recognize from the recruitment process that several dozens of workers had to be recruited for the job, as they had the choice between at least 3 different dates and between 3 different shifts (morning, afternoon, and evening). Note also that the president of the institute is generally known to be a busy man. For instance, he frequently appears on TV and writes for several newspapers. Moreover, at the time, he was the president of the Council of Academic Advisors to the German government. Therefore, we are confident that employees found the explanation for the scarcity of recognition reasonable.

${ }^{21}$ For a group size of 7-8 persons we assigned three thank-you cards, and for a group size of 5-6 persons we assigned two thank-you cards in treatment TC Best3. We control for group size in all regressions. The results are not sensitive to this.
} 


\section{Results}

Table 2 reports descriptive statistics by treatment. The sample from the described treatments contains 340 observations, 81 in Control, 82 in TC All, 95 in TC Best3, and 82 in TC Best $1 .{ }^{22}$ There are statistically significant differences between treatments in some of the observables. However, as shown below, controlling for these characteristics does not alter the results. Treatments are balanced with respect to baseline performance, i.e., performance in the first working period. Throughout the paper, performance is measured as the number of correct entries per minute of working time. ${ }^{23}$

We first examine the main treatment effects. Figure 2 gives a first impression. It shows the average improvement in performance between working periods 1 and 2 for the different treatments. Individuals in the Control treatment show no improvement in performance. By contrast, individuals in treatments with recognition clearly improve their performance. This effect is most pronounced in TC Best 3 . Also, performance improves slightly more in TC Bestl as compared to TC All, suggesting that recognition motivates and that exclusive recognition works better than praising everyone. ${ }^{24}$

This picture is confirmed by a regression analysis. We estimate the following baseline equation:

$$
\begin{aligned}
y_{i, t=2}= & \alpha+\beta_{1} \text { TCAll }+\beta_{2} \text { TCBest } 3+\beta_{3} \text { TCBest } 1 \\
& +\delta_{1} y_{i, t=1}+\delta_{2} y_{i, t=1}^{2}+\delta_{3} y_{i, t=1}^{3}+\sum_{j=2}^{8} \gamma_{j} r_{i, j}+\varepsilon_{i, s},
\end{aligned}
$$

where $y_{i, t}$ represents the performance of individual $i$ in working period $t$. We correct for initial performance differences between individuals by including performance in the first period, linearly as well as squared and cubic. ${ }^{25}$ Additionally, all regressions control for rank-specific effects that are independent of the treatment,

\footnotetext{
${ }^{22}$ In total, 363 persons participated in 48 sessions. We dropped four sessions (two of Control and two of $T C$ All) from the analysis due to severe server breakdowns during working time. Moreover, we excluded two observations as these individuals were hardly able to work on the task due to physical restrictions (one person was visually impaired and could not read the screen, the other person was over 60 years old and did not know how to operate the computer mouse).

${ }^{23}$ One entry corresponds to checking a box of a multiple choice question on the computer screen or typing one word in a free-text field of the data entry surface. Correctness of an individual entry is determined by whether or not it corresponds to what the majority of workers transferred as answer for this particular question. This serves as a very reliable quality measure because each survey was entered on average 21.6 times (s.d.=10.8).

${ }^{24}$ Table B.1 in Appendix B presents the raw means, standard deviations as well as the p-values of the Mann-Whitney rank sum test comparing the recognition treatments with the control treatment.

${ }^{25}$ By controlling for baseline performance in a linear, quadratic, and cubic form, our specification is more flexible than a simple diff-in-diff estimation and allows us to control for mean reversion, for which we find some indication in our data. A standard way to detect mean reversion is to run a simple linear regression for the control group where the standardized performance in period 2 is regressed on the standardized performance in period 1 (Gelman and Hill, 2006). This yields a significant coefficient of the standardized performance in period 1 of 0.85 which indicates some mean reversion. However, since the magnitude of mean reversion is low, we find very similar results if a simple diff-in-diff estimation is applied, that is, regressing treatment dummies on the difference in performance from working period 1 to 2 without controlling for baseline performance. Estimation results are reported in Table B.2 in Appendix B.
} 
where $r_{i, j}$ is a dummy variable taking value one if individual $i$ was of rank $j$ in working period 1 , and taking value zero otherwise. Standard errors are clustered by session.

The first column of Table 3 shows the results of estimating (1), the second column includes gender, field of study, home university, location, time of day, group size, and length of working period 1 as additional controls. ${ }^{26}$ The results of both specifications are similar. As already suggested by Figure 2, recognition has a positive and significant effect on subsequent performance. Recognition which is given to all workers (TC $A l l)$ increases performance by about 0.8 correct entries per minute, which amounts to an increase of $5.2 \%$ (or 0.27 standard deviations). Scarce recognition has a larger estimated effect on performance, as a Wald test on the joint significance of TC Best 3 and TC Best 1 as compared to TC All ( $\mathrm{p}=0.06$, two-sided) indicates. TC Best 3 increases performance by 1.2 clicks per minute, which corresponds to a performance increase of $7.3 \%$ (or 0.38 standard deviations) relative to the control group. The increase in performance in TC Best1 is smaller than in TC Best3, and amounts to 0.9 correct entries per minute (5.6\% or 0.29 standard deviations).

Overall, these results clearly show that performance responds positively to the provision of recognition, suggesting that recognition might be a cost-effective tool to stimulate workers' effort. Our results also suggest that recognition works best when it is scarce, but not too scarce, even though it should be noted that the differences in performance between TC Best 3 and TC All (Wald test, p-value $=0.44$, two-sided) as well as between TC Best 3 and TC Best 1 (Wald test, p-value=0.37, two-sided) are not statistically significant.

In order to shed light on underlying mechanisms and to assess the relevance of the different theories discussed in Section 2, we next look at recipients and non-recipients of recognition separately. Recall that the theories have quite distinct predictions regarding the responses of recipients and non-recipients (see Table 1). Figure 3 gives a first impression of the patterns in the data. The figure shows performance improvements separately for recipients and non-recipients. Recipients increase their performance and this performance increase is slightly decreasing in the scarcity of the recognition. Standard errors are very high for recipients in TC Best 1 due to the small number of observations in this cell. Interestingly, in all treatments where the research assistant was forced to differentiate between employees, the non-recipients subsequently improve by more than the recipients do. The difference is most pronounced for the TC Best 3 treatment, where the improvement of non-recipients is more than twice as large as the improvement of recipients. Hence, the differences between the overall treatment effects that we saw above seem to be mainly driven by the non-recipients rather than the recipients.

An obvious point of criticism on these simple comparisons between recipients and non-recipients is that there is some randomness in employee performance and, thus, we would expect reversion to the mean in the second working period, even in the absence of any treatment. To account for this, we control for baseline performance (linear, squared, and cubic) and baseline rank in all our regressions, so that we compare 'like with like'. Columns III and IV of Table 3 report the results from estimating equation (1)

\footnotetext{
${ }^{26}$ Our results are robust to the inclusion of further controls for different time effects, such as the day of the week or whether the session took place during the final exam period, during the semester, or during semester break. We also ran specifications including interaction terms of treatments with gender and find no evidence for gender-specific treatment effects.
} 
with separate dummy variables for recipients and non-recipients in each treatment. The results confirm the descriptive analysis in Figure 3: positive treatment effects are largely driven by non-recipients. In $T C$ Best3, performance of non-recipients is enhanced by 1.59 clicks per minute which is a $10 \%$ increase (or 0.52 standard deviations) compared to the performance of similar others in the control group. In TC Best1, the improvement is comparatively lower; non-recipients' performance increases by 1.05 clicks per minute which amounts to a $6.6 \%$ higher performance (or 0.34 standard deviations) compared to the control group. Both these differences are statistically significantly different from zero and economically meaningful. The performance differences between non-recipients in TC Best 3 and TC Best 1 are close to significant at the $10 \%$ level (Wald test: $\mathrm{p}=0.11$, two-sided). Recipients, by contrast, do not show a statistically significant difference in performance in TC Best3, and even a slightly lower performance in TC Best1, as compared to similar others in control. ${ }^{27}$ The difference between recipients and non-recipients is significant at the $5 \%$ level in TC Best 3 (Wald test: $\mathrm{p}=0.03$, two-sided), and marginally significant in TC Best 1 (Wald test: $\mathrm{p}=0.11$, two-sided). ${ }^{28}$

We have seen that recognition has a strong positive impact on subsequent performance, in particular when recognition is scarce, but not too scarce. This effect is primarily caused by the improvement in performance of those who did not receive recognition. How can we reconcile these findings with the theories discussed in Section 2? Our results seem most consistent with individuals having a preference for conformity and being reciprocal at the same time. The strong performance improvement of non-recipients is well in line with conformity theory. ${ }^{29}$ Moreover, the fact that the improvement in productivity of non-recipients is larger in TC Best 3 than in TC Best1 nicely fits with the predictions of conformity preferences. At the same time, however, conformity theory cannot explain the increase in performance in TC All. Further, in isolation, conformity theory would predict that recipients of scarce recognition reduce their performance, while we find a small increase in TC Best3 as compared to control. Hence, it seems likely that employee behavior is also partly driven by reciprocity, which explains these positive level-effects. This reciprocity may either stem from an inclination to return a gift or from signaling, or a combination of the two. The data do not allow us to distinguish between these forms of reciprocity in a meaningful way.

\footnotetext{
${ }^{27}$ We can rule out that recipients do not respond because they are at their maximum level of performance ('ceiling effects'). Bradler and Neckermann (2013) use the same setup and show that recipients (best 3 performers in the first working period) do increase their performance significantly and substantially subsequent to receiving a combination of recognition and money.

${ }^{28}$ The data also allows us to analyze treatment effects separately for quantity and quality, where quality is measured as the error rate (percentage of incorrect entries). We find no significant treatment effects for quality levels except for a smaller error rate in $T C$ All (significant at the 10 percent level). One reason for small effects on the error rate is that quality levels are already at a very high level in working period 1 (only $1.5 \%$ of all entries were incorrect), leaving little room for improvement. Treatment effects on total productivity and quality are reported in Table B.3 in Appendix B.

${ }^{29}$ Recall that in the treatments with scarce recognition the research assistant told the employees that she did not have any further thank-you cards to distribute, rendering it unlikely that the performance increase of the non-recipients that we observe here is caused by non-recipients' expectation of and striving for another round of cards at the end of working period 2. A further reason to be skeptical about this alternative explanation is that Bradler et al. (2013b) do not find any evidence for incentive effects of announced thank-you cards to the three best performing workers in an identical setup.
} 


\section{Conclusion}

In a controlled workplace context, we have shown that unannounced provision of public recognition to employees causes a statistically and economically significant increase in performance. Further, our results suggest that recognition works best when it is provided exclusively, but not too exclusively. In groups of eight workers, recognition to the best three performers led to a stronger performance increase than either recognition to all employees or recognition to the best performer. However, these differences are not statistically significant. Interestingly, the performance increases in response to exclusive recognition are mainly driven by strong positive responses of non-recipients. Conformity preferences are the most likely reason for these responses. Upon learning that one does not belong to the best three performers in a group of eight, non-recipients apparently feel inclined to improve performance so as to adhere to the apparent work norm. In line with this interpretation, we find weaker (but still positive) responses of non-recipients when only the best performer in a group received recognition, as this is a weaker signal of low relative performance than belonging to the bottom five out of eight workers. However, conformity preferences cannot explain all of our results. In particular, recipients of recognition do not decrease performance, as conformity would suggest. Moreover, we find that recognition for all workers in a group increases performance. A natural candidate to reconcile these findings is that, in addition to conformity preferences, workers are also reciprocal and hence increase performance in response to recognition.

Our findings have clear management implications. On the one hand, the results suggest that recognition can be a cost-effective tool for increasing average effort, especially when recognition is provided to a substantial subset of high performers. On the other hand, managers need to take into account that the provision of scarce recognition provides information to workers about the work norm prevalent in the group. Depending on the circumstances, this may or may not be beneficial for the organization. For instance, when organizational performance is particularly determined by the best performing workers, scarce recognition may have limited or even adverse effects. In such cases, providing recognition to all employees is likely to be a better alternative, as doing so is more likely to boost performance of top performers. ${ }^{30}$

The current experiment raises a number of issues that remain open for future research. Since the performance increase was primarily driven by non-recipients, a similar effect might be reached at lower cost with pure relative performance information. ${ }^{31}$ Interesting follow-up treatments would either only provide

\footnotetext{
${ }^{30}$ Unreported regressions show that the estimated effect of recognition in $T C A l l$ is rather homogeneous across the performance distribution, i.e. the estimated effect size for the three best workers in a work session is comparable to the estimated effect size for the bottom five.

${ }^{31}$ Neckermann and Yang (2012) report the results of a lab experiment with a similar setup. In the experiment, five agents work for one principal on a real-effort task. The profit of the principal depends on the effort of the agents. In one treatment, participants learned about the identities of the top three performers in the group (pure information). In two other treatments, the principal could opt for a message of recognition or a financial bonus to the top three performers. They find that non-recipients increase their effort similarly in all treatments. This suggests that the information per se rather than the rewards drives the response of non-recipients. Interestingly, the authors do not find significant performance responses from the recipients in any of their treatments, which is in line with the current study. Ashraf et al. (2014b) and Schultz et al. (2007) also disentangle the effects of recognition and feedback
} 
relative performance information or use scarce rewards, but hand them out randomly, independent of past performance. Further, in our experiment we justified the scarcity of recognition by pointing to managerial time constraints. It would be interesting to see whether behavioral patterns change when it is stated that recognition is made scarce deliberately, i.e. when the manager states that she wishes to recognize only the best-performing workers. This may dramatically change the signal provided through scarce recognition about the manager's characteristics. Moreover, to assess the robustness of the results, it would be fruitful to replicate the design with more experienced workers and in a setting where other incentives are present. Stajkovic and Luthans (2003), Ashraf et al. (2014b), Bareket-Bojmel et al. (2014), and Neckermann et al. (2014) report positive effects of recognition in such settings. Interestingly, like us, Bareket-Bojmel et al. (2014) find evidence for a reciprocal response of employees to the provision of thank-you cards. As an example from a different context, Hoogveld and Zubanov (2014) replicate our study in an undergraduate microeconomics course. They provide unexpected public recognition in a random subset of tutorial groups to the $30 \%$ best students of the group. Their findings correspond to ours, in that recognition has a particularly positive effect on the performance of non-recipients.

Another interesting follow-up study could look at how long the effects persist and whether the effects remain of similar size when recognition is provided repeatedly. There are two reasons why we think this is particularly relevant in our context. First, we study recognition that comes as a surprise, which raises the issue whether the surprise element can be maintained. Clearly, when recognition is provided repeatedly in the exact same manner, the effect may soon disappear. Such recognition is no longer personal and thoughtful, and workers will most likely start to doubt the manager's motives. Managers therefore need to think about different ways of recognizing workers to ensure that their recognition remains effective. ${ }^{32}$ In line with this, Rogers and Frey (2014) argue that treatment effects of stimuli are generally more likely to show up repeatedly when a surprise element is maintained, for instance when the treatment is provided irregularly, when the time intervals between repetitions are long, and when the treatment is not presented in the same way every time (see also McSweeney, 2004). Second, our findings suggest that scarce recognition is particularly effective because it provides information on the work norm. Can we expect workers to react to this information when the same information is provided repeatedly? Recent evidence in the context of energy conservation suggests that regular information provision can be remarkably powerful even after many repetitions. Allcott and Rogers (2014) show, using a field experiment, that consumers continue to respond to monthly feedback on their energy consumption after more than two years of treatment. This effect comes on top of the post-treatment effect: consumers who are discontinued from treatment after two years continue to consume less energy than the control group, but consume more than the group that still receives feedback. Apparently, feedback is either still informative after two years, or people need frequent reminders of what

in different contexts. Schultz et al. (2007) find a positive response of individuals with below median performance which is entirely driven by feedback, while Ashraf et al. (2014b) report negative responses of underperforming individuals to feedback. Both find positive responses to recognition.

${ }^{32}$ The success of books such as '1001 Ways to Reward Employees' (Nelson, 2005) suggests that managers acknowledge this need. 
they know already.

More generally, it would be helpful if future studies provide further evidence about the effects of different forms of recognition in different circumstances. Given the wide variety in those two dimensions, the results of a single study on the effects of recognition, by their nature, may not generalize far beyond the specific setting in which it is conducted. ${ }^{33}$ This underlines the need for future studies. We hope that the findings of our paper will encourage researchers and organizations to join forces and set up field experiments so as to learn about the effects of different forms of recognition in a wide variety of workplace contexts.

\footnotetext{
${ }^{33}$ See Al-Ubaydli and List (2013) for an insightful discussion on the generalizability of experimental results in economics.
} 


\section{References}

Akerlof, G. A., 1982. Labor contracts as partial gift exchange. Quarterly Journal of Economics 97 (4), 543-69.

Al-Ubaydli, O., Andersen, S., Gneezy, U., List, J. A., 2014. Carrots that look like sticks: Toward an understanding of multitasking incentive schemes. Forthcoming in Southern Economic Journal.

Al-Ubaydli, O., List, J. A., 2013. On the generalizability of experimental results in economics: With a response to Camerer, NBER Working Paper no. 19666.

Allcott, H., Rogers, T., 2014. The short-run and long-run effects of behavioral interventions: Experimental evidence from energy conservation. American Economic Review 104(10), 3003-3037.

Alpizar, F., Carlsson, F., Johansson-Stenman, O., 2008. Anonymity, reciprocity, and conformity: Evidence from voluntary contributions to a national park in Costa Rica. Journal of Public Economics 92(5-6), 1047-1060.

Anderson, A., Huttenlocher, D., Kleinberg, J., Leskovec, J., 2013. Steering user behavior with badges. In: Proceedings of the 22nd international conference on World Wide Web. International World Wide Web Conferences Steering Committee, pp. 95-106.

Ashraf, N., Bandiera, O., Jack, K., 2014a. No margin, no mission? A field experiment on incentives for public service delivery. Journal of Public Economics 120, 1-17.

Ashraf, N., Bandiera, O., Lee, S. S., 2014b. Awards unbundled: Evidence from a natural field experiment. Journal of Economic Behavior \& Organization 100, 44-63.

Azmat, G., Iriberri, N., 2010. The importance of relative performance feedback information: Evidence from a natural experiment using high school students. Journal of Public Economics 94 (7-8), 435-452.

Bandiera, O., Larcinese, V., Rasul, I., 2009. Blissful ignorance? Evidence from a natural experiment on the effect of individual feedback. Mimeo, London School of Economics and Political Science.

Barankay, I., 2011a. Rank incentives: Evidence from a randomized workplace experiment. Mimeo, University of Pennsylvania.

Barankay, I., 2011b. Rankings and social tournaments: Evidence from a crowd-sourcing experiment. Mimeo, University of Pennsylvania.

Bareket-Bojmel, L., Hochman, G., Ariely, D., 2014. It's (not) all about the Jacksons - Testing different types of short-term bonuses in the field. Forthcoming in Journal of Management. 
Benabou, R., Tirole, J., 2003. Intrinsic and extrinsic motivation. The Review of Economic Studies 70 (3), 489-520.

Bernheim, B. D., 1994. A theory of conformity. Journal of Political Economy 102 (5), 841-877.

Bicchieri, C., Xiao, E., 2009. Do the right thing: but only if others do so. Journal of Behavioral Decision Making 22 (2), 191-208.

Blanes i Vidal, J., Nossol, M., 2011. Tournaments without prizes: Evidence from personnel records. Management Science 57 (10), 1721-1736.

Blau, P. M., 1964. Exchange and Power in Social Life. John Wiley, New York.

Bobek, D. D., Roberts, R. W., Sweeney, J. T., 2007. The social norms of tax compliance: Evidence from Australia, Singapore, and the United States. Journal of Business Ethics 74 (1), 49-64.

Bradler, C., Dur, R., Neckermann, S., Non, A., 2013a. Employee recognition and performance: A field experiment. Centre for European Economic Research Discussion Paper No. 13-017.

Bradler, C., Dur, R., Neckermann, S., Non, A., 2013b. Reward expectancy and performance: A field experiment. Mimeo.

Bradler, C., Neckermann, S., 2013. Money meets recognition: A field experiment on worker effort. Mimeo, Centre for European Economic Research, Mannheim.

Cameron, J., Pierce, W., 1994. Reinforcement, reward, and intrinsic motivation - A meta-analysis. Review of Educational Research 64 (3), 363-423.

Charness, G., Masclet, D., Villeval, M.-C., 2014. The dark side of competition for status. Management Science 60(1), 38-55.

Chen, Y., Harper, F. M., Konstan, J., Li, S. X., 2010. Social comparisons and contributions to online communities: A field experiment on movielens. American Economic Review 100 (4), 1358-98.

Cropanzano, R., Mitchell, M. S., 2005. Social exchange theory: An interdisciplinary review. Journal of Management 31 (6), 874-900.

Danilov, A., Sliwka, D., 2013. Can contracts signal social norms? experimental evidence. IZA Discussion Paper.

Deci, E. L., Ryan, R. M., 1971. Effects of externally mediated rewards on intrinsic motivation. Journal of Personality and Social Psychology 18 (1), 105-115.

Delfgaauw, J., Dur, R., Sol, J., Verbeke, W., 2013. Tournament incentives in the field: Gender differences in the workplace. Journal of Labor Economics 31(2), 305-326. 
Dur, R., 2009. Gift exchange in the workplace: Money or attention? Journal of the European Economic Association 7 (2-3), 550-560.

Ellingsen, T., Johannesson, M., 2008. Pride and prejudice: The human side of incentive theory. American Economic Review 98 (3), 990-1008.

Falk, A., Fischbacher, U., 2006. A theory of reciprocity. Games and Economic Behavior 54 (2), 293-314.

Falk, A., Ichino, A., 2006. Clean evidence on peer effects. Journal of Labor Economics 24 (1), 39-58.

Fehr, E., Kirchsteiger, G., Riedl, A., 1993. Does fairness prevent market clearing? An experimental investigation. Quarterly Journal of Economics 108 (2), 437-59.

Fischer, P., Huddart, S., 2008. Optimal contracting with endogenous social norms. American Economic Review 98 (4), 1459-1475.

Fisher, R. J., Ackerman, D., 1998. The effects of recognition and group need on volunteerism: A social norm perspective. Journal of Consumer Research 25 (3), 262-75.

Freeman, R. B., Gelber, A. M., 2010. Prize structure and information in tournaments: Experimental evidence. American Economic Journal: Applied Economics 2 (1), 149-64.

Frey, B. S., Meier, S., 2004. Social comparisons and pro-social behavior: Testing conditional cooperation in a field experiment. American Economic Review 94 (5), 1717-1722.

Gelman, A., Hill, J., 2006. Data analysis using regression and multilevel/hierarchical models. Cambridge University Press.

Gerber, A. S., Rogers, T., 2009. Descriptive social norms and motivation to vote: everybody's voting and so should you. The Journal of Politics 71 (01), 178-191.

Gneezy, U., List, J., 2006. Putting behavioral economics to work: Field evidence on gift exchange. Econometrica 74 (5), 1365-1384.

Grant, A. M., Gino, F., 2010. A little thanks goes a long way: Explaining why gratitude expressions motivate prosocial behavior. Journal of Personality and Social Psychology 98 (6), 946-955.

Gubler, T., Larkin, I., Pierce, L., 2013. The dirty laundry of employee award programs: Evidence from the field. Harvard Business School NOM Unit Working Paper 13-069.

Gul, F., Pesendorfer, W., 2010. Interdependent preference models as a theory of intentions. Forthcoming in Journal of Economic Theory.

Harrison, G. W., List, J. A., 2004. Field experiments. Journal of Economic Literature 42 (4), 1009-1055. 
Hennig-Schmitt, H., Rockenbach, B., Sadrieh, A., 2010. In search of worker's real effort reciprocity - A field and a laboratory experiment. Journal of the European Economic Association 8 (4), 817-837.

Holton, V., Dent, F., Rabbetts, J., 2009. Motivation and employee engagement in the 21st century: A survey of management views. An Ashridge Report.

Hoogveld, N., Zubanov, N., 2014. The power of (no) recognition: Experimental evidence from the university classroom. IZA Discussion Paper no. 7953.

Kosfeld, M., Neckermann, S., 2011. Getting more work for nothing? Symbolic awards and worker performance. American Economic Journal: Microeconomics 3 (3), 1-16.

Kovach, K. A., 1995. Employee motivation: Addressing a crucial factor in your organization's performance. Employment Relations Today 22 (2), 93-107.

Kube, S., Maréchal, M. A., Puppe, C., 2012. The currency of reciprocity - Gift exchange in the workplace. American Economic Review 102 (4), 1644-62.

Kube, S., Maréchal, M. A., Puppe, C., 2013. Do wage cuts damage work morale? Evidence from a natural field experiment. Journal of the European Economic Association 11(4), 853-870.

Kuhnen, C. M., Tymula, A., 2012. Feedback, self-esteem and performance in organizations. Management Science 58 (1), 94-113.

Levine, D. K., 1998. Modeling altruism and spitefulness in experiments. Review of Economic Dynamics $1(3), 593-622$.

Levitt, S., List, J. A., 2009. Field experiments in economics: The past, the present, and the future. European Economic Review 53 (1), 1-18.

List, J. A., Rasul, I., 2011. Field experiments in labor economics. In: Ashenfelter, O., Card, D. (Eds.), Handbook of Labor Economics, 1st Edition. Vol. 4. Elsevier, pp. 103-228.

McSweeney, F. K., 2004. Dynamic changes in reinforcer effectiveness: Satiation and habituation have different implications for theory and practice. Behavior Analyst 27 (2), 171-188.

Neckermann, S., Cueni, R., Frey, B. S., 2014. Awards at work. Forthcoming in Labour Economics.

Neckermann, S., Yang, X., 2012. The impact of scarce rewards on worker effort: An experimental investigation. Mimeo.

Nelson, B., 2005. 1001 ways to reward employees. Vol. 2. Workman Publishing Company, New York.

Nolan, J. M., Schultz, P. W., Cialdini, R. B., Goldstein, N. J., Griskevicius, V., 2008. Normative social influence is underdetected. Personality and Social Psychology Bulletin 34 (7), 913-923. 
Non, A., 2012. Gift-exchange, incentives, and heterogeneous workers. Games and Economic Behavior 75 (1), 319-336.

Rhoades, L., Eisenberger, R., 2002. Perceived organizational support: A review of the literature. Journal of Applied Psychology 87 (4), 698-714.

Rogers, T., Frey, E., 2014. Changing behavior beyond the here and now. HKS Faculty Research Working Paper Series RWP14-014.

Schultz, P. W., Nolan, J. M., Cialdini, R. B., Goldstein, N. J., Griskevicius, V., 2007. The constructive, destructive, and reconstructive power of social norms. Psychological Science 18, 429-434.

Shang, J., Croson, R., 2009. A field experiment in charitable contribution: The impact of social information on the voluntary provision of public goods. The Economic Journal 119 (540), 1422-1439.

Sliwka, D., 2007. Trust as a signal of a social norm and the hidden costs of incentive schemes. American Economic Review 97 (3), 999-1012.

Stajkovic, A. D., Luthans, F., 2003. Behavioral management and task performance in organizations: Conceptual background, meta-analysis, and test of alternative models. Personnel Psychology 56 (1), $155-194$.

Swank, O. H., Visser, B., 2007. Motivating through delegating tasks or giving attention. Journal of Law, Economics, and Organization 23(3), 731-742.

Tran, A., Zeckhauser, R., 2012. Rank as an inherent incentive: Evidence from a field experiment. Journal of Public Economics 96 (9-10), 645-650.

Wagner, R., Harter, J. K., 2006. 12: The Elements of Great Managing. New York: Gallup Press.

Wiley, C., 1997. What motivates employees what motivates employees according to over 40 years of motivation surveys. International Journal of Manpower 18 (3), 263 - 280. 


\section{Figures}

Figure 1: Thank-you Card

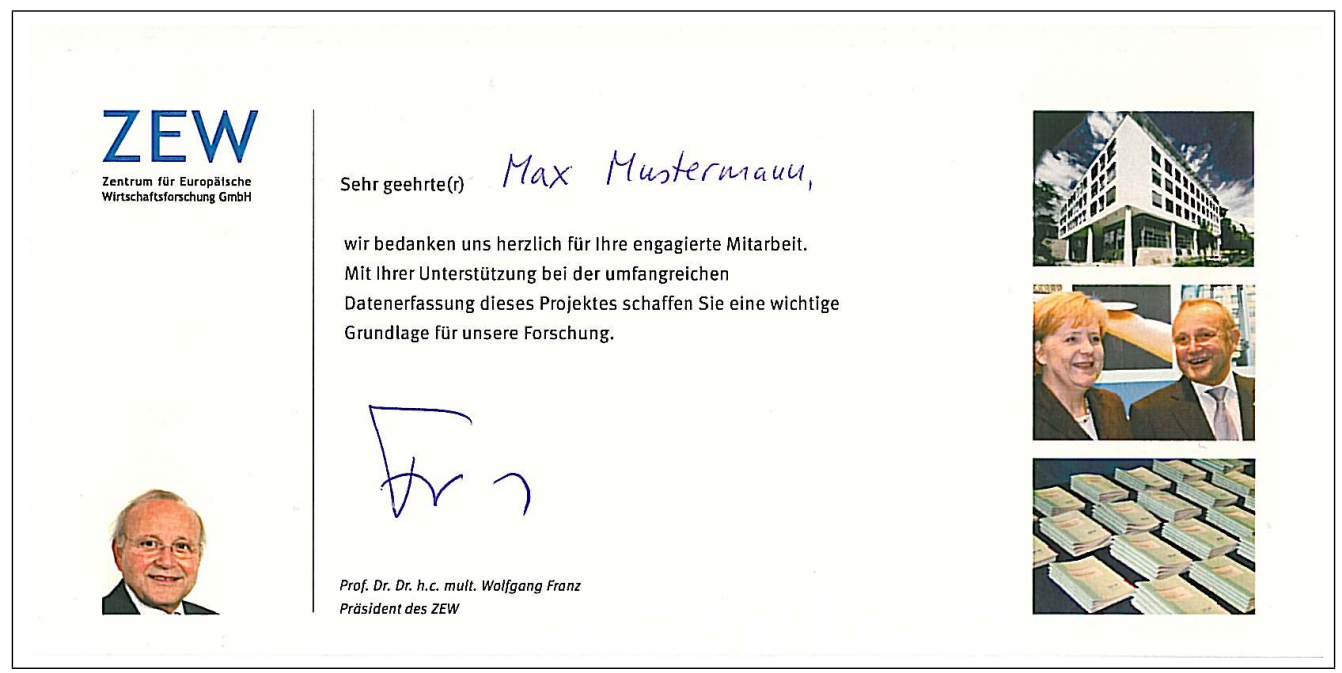

Note: The translation of the text on the card is: "Dear John Public, we would like to thank you cordially for your dedicated work. With your support for this project's comprehensive data-entry, you provide an important basis for our research.". 
Figure 2: Improvement in correct entries per minute by treatment

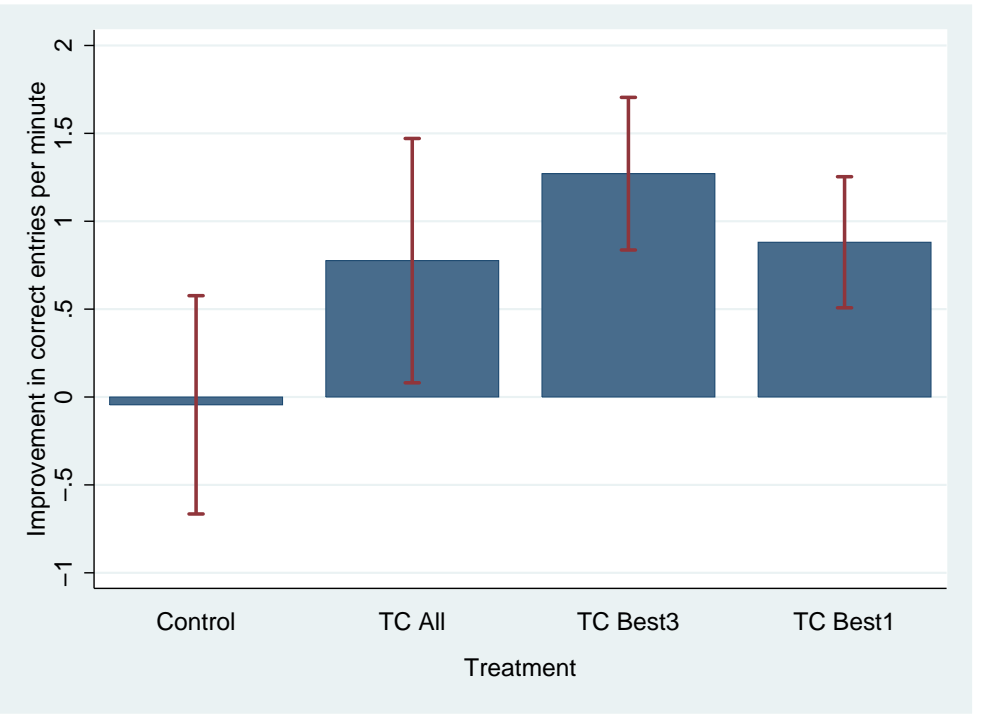

Note: The bars indicate the average change in correct entries from working period 1 to 2 by treatment. The whiskers depict the $95 \%$ confidence intervals based on cluster-adjusted standard errors (clustered on session level). 
Figure 3: Improvement in correct entries per minute by treatment and performance group

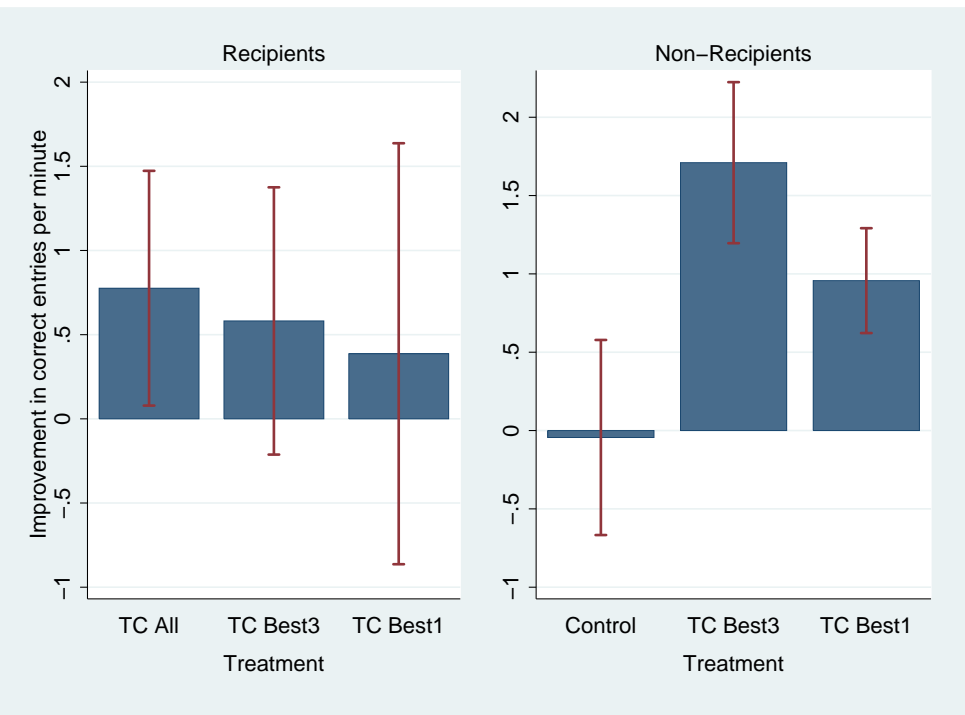

Note: The bars indicate the average change in correct entries from working period 1 to 2 by treatment and performance group. The whiskers depict the $95 \%$ confidence intervals based on cluster-adjusted standard errors (clustered on session level). TC All is included in the left panel as all workers in this treatment receive a card. The Control treatment is included in the right panel as nobody receives a card. 


\section{Tables}

Table 1: Theoretical Predictions

\begin{tabular}{|c|c|c|c|c|c|}
\hline & Card for all & & Card for best 3 & & Card for best 1 \\
\hline Reciprocity & $\mathrm{R}:+$ & $\leq$ & $\begin{array}{l}\mathrm{R}:+ \\
\mathrm{N}: 0\end{array}$ & $\leq$ & $\begin{array}{l}\mathrm{R}:+ \\
\mathrm{N}: 0\end{array}$ \\
\hline $\begin{array}{l}\text { Conditional } \\
\text { altruism }\end{array}$ & + & $>$ & + & $>$ & + \\
\hline Conformity & $\mathrm{R}: 0$ & & $\begin{array}{l}\mathrm{R}:- \\
\mathrm{N}:+\end{array}$ & $>$ & $\begin{array}{l}\mathrm{R}:- \\
\mathrm{N}:+\end{array}$ \\
\hline
\end{tabular}

Note: $\mathrm{R}$ denotes recipients of recognition, $\mathrm{N}$ denotes non-recipients. + and - represent the direction of the predicted performance change. In cases where the theories allow predicting the relative magnitude of the effect in comparison to other treatments, this is indicated with the $<$ or $>$ signs. The first line, for example, reads as follows: Reciprocity theory predicts that recipients of thank you cards respond positively. The size of this effect is either equal across all treatments or increases in size the more exclusive the card is, i.e. the lower the number of recipients relative to non-recipients. 
Table 2: Summary Statistics by Treatment

\begin{tabular}{|c|c|c|c|c|}
\hline & Control & TC All & TC Best 3 & TC Best 1 \\
\hline $\mathrm{N}$ & 81 & 82 & 95 & 82 \\
\hline Female & $\begin{array}{c}0.593 \\
(0.494)\end{array}$ & $\begin{array}{c}0.549 \\
(0.501)\end{array}$ & $\begin{array}{c}0.558 \\
(0.499)\end{array}$ & $\begin{array}{c}0.659 \\
(0.477)\end{array}$ \\
\hline Economics major & $\begin{array}{c}0.383 \\
(0.489)\end{array}$ & $\begin{array}{c}0.317 \\
(0.468)\end{array}$ & $\begin{array}{c}0.368 \\
(0.485)\end{array}$ & $\begin{array}{l}0.512^{*} \\
(0.503)\end{array}$ \\
\hline Mannheim & $\begin{array}{c}0.556 \\
(0.500)\end{array}$ & $\begin{array}{c}0.427 \\
(0.498)\end{array}$ & $\begin{array}{c}0.779 * * * \\
(0.417)\end{array}$ & $\begin{array}{c}0.744^{* *} \\
(0.439)\end{array}$ \\
\hline Morning & $\begin{array}{c}0.407 \\
(0.494)\end{array}$ & $\begin{array}{c}0.317 \\
(0.468)\end{array}$ & $\begin{array}{c}0.389 \\
(0.490)\end{array}$ & $\begin{array}{l}0.268 * \\
(0.446)\end{array}$ \\
\hline Afternoon & $\begin{array}{c}0.235 \\
(0.426)\end{array}$ & $\begin{array}{c}0.402 * * \\
(0.493)\end{array}$ & $\begin{array}{c}0.274 \\
(0.448)\end{array}$ & $\begin{array}{c}0.451 * * * \\
(0.501)\end{array}$ \\
\hline Evening & $\begin{array}{c}0.358 \\
(0.482)\end{array}$ & $\begin{array}{c}0.280 \\
(0.452)\end{array}$ & $\begin{array}{c}0.337 \\
(0.475)\end{array}$ & $\begin{array}{c}0.280 \\
(0.452)\end{array}$ \\
\hline Group size & $\begin{array}{c}6.852 \\
(0.760)\end{array}$ & $\begin{array}{c}7.024 \\
(0.994)\end{array}$ & $\begin{array}{c}7.421 * * * \\
(0.833)\end{array}$ & $\begin{array}{c}7.512 * * * \\
(0.633)\end{array}$ \\
\hline Duration of working period 1 & $\begin{array}{l}96.585 \\
(6.237)\end{array}$ & $\begin{array}{c}102.693^{* * *} \\
(7.516)\end{array}$ & $\begin{array}{c}105.426^{* * * *} \\
(4.127)\end{array}$ & $\begin{array}{c}102.248^{* * * *} \\
(5.100)\end{array}$ \\
\hline Mannheim university & $\begin{array}{c}0.259 \\
(0.441)\end{array}$ & $\begin{array}{c}0.305 \\
(0.463)\end{array}$ & $\begin{array}{c}0.411^{* *} \\
(0.495)\end{array}$ & $\begin{array}{c}0.451 * * \\
(0.501)\end{array}$ \\
\hline Ludwigshafen university & $\begin{array}{c}0.210 \\
(0.410)\end{array}$ & $\begin{array}{c}0.134 \\
(0.343)\end{array}$ & $\begin{array}{c}0.232 \\
(0.424)\end{array}$ & $\begin{array}{c}0.146 \\
(0.356)\end{array}$ \\
\hline Heidelberg university & $\begin{array}{c}0.506 \\
(0.503)\end{array}$ & $\begin{array}{c}0.549 \\
(0.501)\end{array}$ & $\begin{array}{c}0.305 * * * \\
(0.463)\end{array}$ & $\begin{array}{c}0.390 \\
(0.491)\end{array}$ \\
\hline Baseline performance $^{1}$ & $\begin{array}{l}15.873 \\
(3.066)\end{array}$ & $\begin{array}{l}16.628 \\
(3.754)\end{array}$ & $\begin{array}{l}16.191 \\
(4.193)\end{array}$ & $\begin{array}{l}16.528 \\
(3.745)\end{array}$ \\
\hline
\end{tabular}

Note: The table reports means for each group. Standard deviations are displayed in parentheses. Significance levels indicate a difference of means (compared to the control group) and are denoted as follows: $* \mathrm{p}<0.1, * *$ $\mathrm{p}<0.05, * * * \mathrm{p}<0.01$

${ }^{1}$ Baseline performance is measured as correct entries per minute in working period 1. 
Table 3: Treatment Effects on Productivity in Working Period 2

\begin{tabular}{lcccc}
\hline \hline & I & II & III & IV \\
\hline TC All & $0.839^{*}$ & $0.818^{*}$ & $0.845^{*}$ & $0.828^{*}$ \\
& $(0.439)$ & $(0.433)$ & $(0.440)$ & $(0.434)$ \\
TC Best3 & $1.272^{* * *}$ & $1.163^{* * *}$ & & \\
& $(0.386)$ & $(0.408)$ & & \\
TC Best1 & $0.941^{* *}$ & $0.882^{* *}$ & & \\
& $(0.385)$ & $(0.386)$ & & \\
TC Best3 - Rec. & & & 0.647 & 0.515 \\
& & & $(0.518)$ & $(0.535)$ \\
TC Best3 - Non-Rec. & & & $1.698^{* * *}$ & $1.588^{* * *}$ \\
& & & $(0.407)$ & $(0.430)$ \\
TC Best1 - Rec. & & & 0.043 & -0.046 \\
& & & $(0.761)$ & $(0.757)$ \\
TC Best1 - Non-rec. & & & $1.100^{* * *}$ & $1.046^{* * *}$ \\
& & & $(0.377)$ & $(0.382)$ \\
Controls & & & & \\
Baseline performance & Yes & Yes & Yes & Yes \\
Demographics & No & Yes & No & Yes \\
Other controls & No & Yes & No & Yes \\
\hline Observations & 627 & 627 & 627 & 627 \\
Sessions & 91 & 91 & 91 & 91 \\
$R^{2}$ & 0.776 & 0.780 & 0.779 & 0.783 \\
\hline \hline
\end{tabular}

Note: This table reports OLS coefficient estimates (standard errors clustered by session are reported in parentheses). The dependent variable is a worker's performance in the second working period measured by the number of correct database entries per minute. TC All represents the treatment where all workers in a work group received a thank-you card after the first working period. TC Best 3 and TC Best1 refer to sessions where thank-you cards were assigned to either the best three or the best performing workers, respectively. Treatment Control is omitted and serves as the reference category. All columns include controls for baseline performance, its squared and cubic term, as well as the performance rank of workers in working period 1. Column II includes additional controls for demographics such as gender, university and field of study as well as other controls such as location, time of day, duration of working period 1 and group size. Column III allows for differential treatment effects for recipients (Rec.) and non-recipients (Non-Rec.) of thank-you cards. Column IV additionally includes all control variables. Note that all regressions also include dummies for and observations from four other treatments, which are reported in Bradler and Neckermann (2013) and Bradler et al. (2013b). The data are included to obtain more accurate estimates of the coefficients for the control variables. Significance levels are denoted as follows: $* p<0.1$, $* * \mathrm{p}<0.05, * * * \mathrm{p}<0.01$. 


\section{Appendix A: Treatment Scripts (Original in German)}

\section{Control:}

"May I bother you for a moment? With the help of our IT department, we did a brief check of the server. The data have been correctly transmitted from all computers so far. We were previously struggling with some software problems but now everything seems to work fine."

\section{Thank-you card for all (TC All):}

"May I bother you for a moment? With the help of our IT department, we did a brief check of the server. The data have been correctly transmitted from all computers so far. We were previously struggling with some software problems but now everything seems to work fine. We would also like to take the opportunity to thank you in advance for your help. In preparation for this data-entry job, our president, Wolfgang Franz, and we have decided to give everyone this thank-you card as a symbol of our appreciation and thankfulness for your support. [While assigning the cards:] Thank you very much for your commitment!"

\section{Thank-you card for best 3 (TC Best3):}

"May I bother you for a moment? With the help of our IT department, we did a brief check of the server. The data have been correctly transmitted from all computers so far. We were previously struggling with some software problems but now everything seems to work fine. We would also like to take the opportunity to thank you in advance for your help. In preparation for this data-entry job, our president, Wolfgang Franz, and we have decided to give everyone this thank-you card as a symbol of our appreciation and thankfulness for your support. However, Prof. Franz was only able to sign a small number of cards personally. Therefore, we have decided just now to hand these cards to those of you who entered most data so far. Our IT-specialists have told us that logins A, B, and C have transmitted most data so far. This should be Mr. /Mrs. X, Y, and Z, correct? [While assigning the cards:] A special thank to you, Mr./Ms. X, Y, and Z for your commitment."

\section{Thank-you card for best 1 (TC Best1):}

"May I bother you for a moment? With the help of our IT department, we did a brief check of the server. The data have been correctly transmitted from all computers so far. We were previously struggling with some software problems but now everything seems to work fine. We would also like to take the opportunity to thank you in advance for your help. In preparation for this data-entry job, our president, Wolfgang Franz, and we have decided to give everyone this thank-you card as a symbol of our appreciation and thankfulness for your support. However, Prof. Franz was only able to sign a small number of cards personally. Therefore, we have decided just now to hand the card to that person who entered most data so far. Our IT-specialists have told us that login A has transmitted most data so far. This should be Mr./Mrs. X, correct? [While handing over the card:] A special thank to you, Mr./Ms. X for your commitment." 


\section{Appendix B: Supplementary Tables}

Table B.1: Improvement in correct entries per minute after treatment intervention by treatment

\begin{tabular}{lcc}
\hline \hline & $\begin{array}{c}\text { Mean } \\
(\mathrm{sd})\end{array}$ & $\begin{array}{c}\text { Mann-Whitney rank-sum test } \\
\text { vs. Control } \\
\text { p-value }\end{array}$ \\
& & \\
Control & -0.044 & \\
& $(1.964)$ & $0.006^{* * *}$ \\
TC All & 0.776 & \\
& $(2.374)$ & $0.000^{* * *}$ \\
TC Best3 & 1.271 & \\
& $(1.820)$ & $0.005^{* * *}$ \\
TC Best1 & 0.880 & \\
& $(1.811)$ & \\
\hline \hline
\end{tabular}

Note: Standard deviations are reported in parentheses. Significance levels are denoted as follows: $* \mathrm{p}<0.1, * * \mathrm{p}<0.05, * * * \mathrm{p}<0.01$. 
Table B.2: Simple Diff-in-Diff Estimation of Treatment Effects on the Difference in Productivity between Working Periods 2 and 1

\begin{tabular}{|c|c|c|c|c|}
\hline & I & II & III & IV \\
\hline TC All & $\begin{array}{l}0.820 * \\
(0.474)\end{array}$ & $\begin{array}{l}0.804 * \\
(0.462)\end{array}$ & $\begin{array}{l}0.820 * \\
(0.475)\end{array}$ & $\begin{array}{l}0.802 * \\
(0.463)\end{array}$ \\
\hline TC Best3 & $\begin{array}{c}1.315^{* * * *} \\
(0.385)\end{array}$ & $\begin{array}{c}1.277 * * * \\
(0.411)\end{array}$ & & \\
\hline TC Best1 & $\begin{array}{c}0.925 * * \\
(0.368)\end{array}$ & $\begin{array}{c}0.915^{* *} \\
(0.372)\end{array}$ & & \\
\hline TC Best3 - Rec. & & & $\begin{array}{c}0.626 \\
(0.512)\end{array}$ & $\begin{array}{c}0.557 \\
(0.524)\end{array}$ \\
\hline TC Best3 - Non-Rec. & & & $\begin{array}{c}1.755 * * * \\
(0.410)\end{array}$ & $\begin{array}{c}1.730 * * * \\
(0.446)\end{array}$ \\
\hline TC Best1 - Rec. & & & $\begin{array}{c}0.431 \\
(0.710)\end{array}$ & $\begin{array}{c}0.399 \\
(0.700)\end{array}$ \\
\hline TC Best1 - Non-rec. & & & $\begin{array}{c}1.001 * * * \\
(0.359)\end{array}$ & $\begin{array}{c}1.001 * * * \\
(0.368)\end{array}$ \\
\hline \multicolumn{5}{|l|}{ Controls } \\
\hline Demographics & No & Yes & No & Yes \\
\hline Other controls & No & Yes & No & Yes \\
\hline Observations & 627 & 627 & 627 & 627 \\
\hline Sessions & 91 & 91 & 91 & 91 \\
\hline$R^{2}$ & 0.082 & 0.092 & 0.096 & 0.108 \\
\hline
\end{tabular}

Note: This table reports OLS coefficient estimates (standard errors clustered by session are reported in parentheses). The dependent variable is the difference in correct entries per minute between working period 2 and working period 1. TC All represents the treatment where all workers in a work group received a thank-you card after the first working period. TC Best3 and TC Best 1 refer to sessions where thank-you cards were assigned to either the best three or the best performing workers, respectively. Treatment Control is omitted and serves as the reference category. Column I and II shows overall treatments effects. Column III and IV allows for differential treatment effects for recipients (Rec.) and non-recipients (Non-Rec.) of thank-you cards. Columns II and IV include additional controls for demographics such as gender, university and field of study as well as other controls such as location, time of day, duration of working period 1 and group size. Note that all regressions also include dummies for and observations from four other treatments, which are reported in Bradler and Neckermann (2013) and Bradler et al. (2013b). The data are included to obtain more accurate estimates for the coefficients of the control variables. Significance levels are denoted as follows: $* \mathrm{p}<0.1, * * \mathrm{p}<0.05, * * * \mathrm{p}<0.01$. 
Table B.3: Treatment Effects on Total Productivity and Error Rates in Working Period 2

\begin{tabular}{lcc|cc}
\hline \hline & \multicolumn{2}{c}{ Total Productivity } & \multicolumn{2}{c}{ Error Rate } \\
& I & II & III & IV \\
\hline TC All & 0.688 & 0.697 & $-0.589^{* *}$ & $-0.592^{* *}$ \\
& $(0.432)$ & $(0.432)$ & $(0.262)$ & $(0.264)$ \\
TC Best3 & $1.167^{* * *}$ & & 0.140 & \\
& $(0.427)$ & & $(0.258)$ & \\
TC Best1 & $0.846^{* *}$ & & -0.188 & \\
& $(0.402)$ & & $(0.204)$ & \\
TC Best3 - Rec. & & 0.425 & & -0.136 \\
& & $(0.550)$ & & $(0.275)$ \\
TC Best3 - Non-Rec. & & $1.661 * * *$ & & 0.305 \\
& & $(0.446)$ & & $(0.318)$ \\
TC Best1 - Rec. & & -0.109 & & -0.304 \\
& & $(0.780)$ & & $(0.235)$ \\
TC Best1 - Non-rec. & & $1.021^{* *}$ & & -0.169 \\
& & $(0.396)$ & & $(0.219)$ \\
Controls & & & & \\
Baseline performance & Yes & Yes & Yes & Yes \\
Demographics & Yes & Yes & Yes & Yes \\
Other controls & Yes & Yes & Yes & Yes \\
\hline Observations & 627 & 627 & 627 & 627 \\
Sessions & 91 & 91 & 91 & 91 \\
$R^{2}$ & 0.780 & 0.783 & 0.475 & 0.478 \\
\hline \hline
\end{tabular}

Note: This table reports OLS coefficient estimates (standard errors clustered by session are reported in parentheses). The dependent variable is a worker's performance in the second working period measured by the number of correct database entries per minute. TC All represents the treatment where all workers in a work group received a thank-you card after the first working period. TC Best 3 and TC Best1 refer to sessions where thank-you cards were assigned to either the best three or the best performing workers, respectively. Treatment Control is omitted and serves as the reference category. In columns I and II, the dependent variable is a worker's total number of entries made in the second working period. In columns III and IV, the dependent variable is a worker's error rate in the second working period. The error rate is calculated by dividing total errors by total entries entered. All columns include controls for baseline performance, its squared and cubic term, as well as the performance rank of workers in working period 1. Baseline performance is measured as the number of entries in working period 1 in columns I and II, and the error rate in working period 1 in columns III and IV, respectively. Further, all regressions include controls for demographics such as gender, university and field of study as well as other controls such as location, time of day, duration of working period 1 and group size. Column II and IV allow for differential treatment effects for recipients (Rec.) and non-recipients (Non-Rec.) of thank-you cards. Note that all regressions also include dummies for and observations from four other treatments, which are reported in Bradler and Neckermann (2013) and Bradler et al. (2013b). The data are included to obtain more accurate estimates for the coefficients for the control variables. Significance levels are denoted as follows: $* \mathrm{p}<0.1, * * \mathrm{p}<0.05, * * * \mathrm{p}<0.01$. 